\title{
IT FOR LEARNING: A NEED FOR A NEW APPROACH?
}

\author{
Anita Kollerbaur \\ Department of Computer and Systems Sciences (DSV), Stockholm University/Royal Institute \\ of Technology; anita@dsv.su.se
}

Abstract: This paper presents the development and use of IT for learning in Sweden during the period 1966-1986. An overview of the major activities and course of events has two phases of categorization: 1966-1973 as the orientation period and 1973-1986 as the research period. This paper describes the research project PRINCESS in some detail. PRINCESS adopted a cognitive approach to the use of IT for learning, applied an interdisciplinary, and a systems thinking approach to research. A holistic model was developed and studied empirically in several stages. The results presented 1983 are summarized, most of them are still sustainable. The impact of PRINCESS in schools and in academia is briefly discussed. Based on the experiences from more than 20 years of own research in the area, some possible explanations are elaborated on why we still after some 40 years and despite the technical development, not seem to be able to utilize the real prospects of IT for learning. The conclusion is that we probably need a new approach to IT and learning and sketch a vision for a future learning environment.

Key words: IT for learning, interaction, iterative design methods, object orientation

\section{INTRODUCTION}

It is often believed that e-learning (or the use of IT for learning) is an application introduced during the 1990s. However, the first steps were already in place in 1959 in the US and in the mid 1960s in Sweden.

There are many interpretations of the meaning of e-learning; a common one seems to be the use of Internet in education. Lately, significant 
investments in e-learning have occurred; many have failed while some were successful. Nevertheless, the boom for IT for learning has still not appeared.

Reflections in this paper are mainly based on the research in the PRINCESS project ${ }^{23}$ (Project for Research on Interactive Computer-based Education Systems) and in the research group CLEA (Computer-based Learning Environments, 1973-1986..$^{27,29}$ To facilitate for the interested reader the reference list includes other material.

\section{AN OVERVIEW OF THE DEVELOPMENT IN SWEDEN 1966-1986}

\section{$2.1 \quad 1966-1973$ - orientation period}

We characterize the period 1966-1973 as an orientation period including a number of investigations and study trips. It began 1966 with a Swedish delegation studying the use of computers in education in the US. Experiences and recommendations were presented in the report "Datamaskinförmedlad undervisning". ${ }^{2}$ The first initiative was then taken to start experiments in Sweden using a dedicated systems for ComputerAssisted-Instruction(CAI), the IBM 1500 system; however, the idea was turned down.

Nils Lindecrantz $z^{3}$, started a course at the Department of Computer and Systems Sciences (DSV) in 1968 and published a textbook in the area. The course planted the seed that later grew to the PRINCESS project. In 1969, this author received funding for the first field trip to study the Plato-system ${ }^{10}$ at the University of Illinois, at that time the most advanced complete system for computer-based education.

A throughout investigation of the situation in the US up to 1972 was presented by Stiernborg. ${ }^{5}$. Funds for a six-month scholarship to study CAI in the US were through the donation of Dir. Arne Berglund, Mercator International Group, to the Sweden-American Association. As holder of the scholarship, this author did in depth studies of the main systems used in the US $1972-73,{ }^{8}$ resulting in a licentiate thesis in the area $1973 .{ }^{9}$ The thesis included the research plan for the PRINCESS-project.

\section{$2.2 \quad$ Research period 1973-1986}

Beginning in 1972, the authorities changed approach concerning the use of computer-assisted instruction. The Ministry of Education and Science took the initiative to start new investigations. The school authorities of Linköping did a pilot study reported $1973 .^{7}$ This study led to the DIS 
project $^{19}$ (Computer in the School project) within the Swedish National Board of Education (NBE). The goal for the project was to develop an action program for education about computers and their use in Swedish schools. DIS defined three areas for action:

- Education about computers and their use in society

- The use of computers in schools to modernize teaching content in various subjects

- The use of computers as an aid to learning

Lars- Erik Björk, a dedicated mathematics teacher at Sunnerboskolan, played a leading role practically in modernizing math teaching and learning in Sweden and thus strongly influencing the work in DIS.

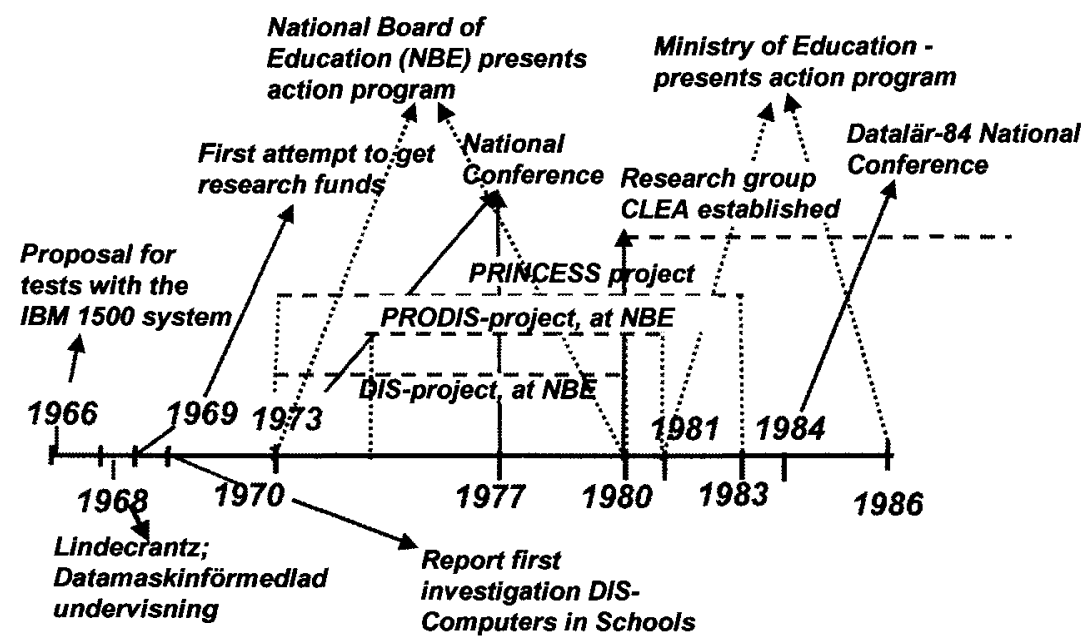

Figure 1. IT-for learning in Sweden 1966-1986. Major activities and courses of events.

Another project, PRODIS $1979-1981,{ }^{22}$ also within NBE, studied the requirements for software to be used within the first two areas. DIS and PRODIS led to compulsory introductory modules about computers and their use in society from the $9^{\text {th }}$ grade and the use of computers in schools to modernize teaching content in various subjects within upper secondary school. State funds were available for purchasing software and hardware. It was also stressed that the use of computers as an aid to learning required research, which lead to the start of the PRINCESS project, Project for Research on INteractive Computer-based Education SystemS in 1973.

PRINCESS formed the base for establishing CLEA (Center for research on interactive Computer-based LEArning environments) $1980-1987$ as one of the first national centers within a program for strengthening the research 
in data processing financed by the Swedish National Board for Technical Development (STU). Within CLEA and its successors, they engaged in a number of projects extending the research in PRINCESS to other areas and perspectives. For instance, research on communicative aspects of interactive systems, the use of the KOM-system for computer supported communication in Swedish communities and studies of visuals for information, such as the use of colors. Research in CLEA was yearly reviewed by international researchers, headed by Professor Arne Sölvberg, NTU, Norway. Review judgments were "excellent". The research is summarized in CLEA progress reports 1980-1987. ${ }^{27,29}$

One mission in PRINCESS and CLEA was to watch the international frontlines in the area in Europe, the US, ${ }^{17}$ and also in $\mathrm{Japan}^{18}$. We made extensive efforts into activities for disseminating information. In 1973, we arranged the first conference in the Parliament Building in Stockholm, presenting the state of the art in the area in Sweden and internationally ${ }^{10}$. The minister of education, Ingvar Carlsson, later prime minister of Sweden, opened the conference. For this time Professor Bitzer, Computer-based Education Research Laboratory (CERL) University of Illinois made a spectacular demonstration of the PLATO IV system by interactively working with the computer system at CERL in the US via the telephone network. The data communicated included advanced graphics.

The 1973 conference led to the national conferences in $1977,{ }^{15} 1984,{ }^{25}$ and $1987 . .^{30,31}$ The proceedings of these conferences also give overviews of other Swedish activities than within PRINCESS and CLEA. Further PRINCESS took the responsibility of disseminating the results to a broad public audience. A brochure, in English and in Swedish was produced and distributed to all Swedish schools, politicians, decision-makers and parties interested in the use of computer-aids in education ${ }^{23}$.

\section{PRINCESS PROJECT 1973-1983}

\subsection{Background and general information}

The PRINCESS-project started after four years of funding efforts. By then the group already had substantial knowledge in the area from internal projects at $\mathrm{DSV}^{11}$ as well as from a series of studies of the situation in the US $^{8}$ and a licentiate thesis. ${ }^{9}$ Since this was the first research project in Sweden in the area and a female researcher led it, the project received significant recognition.

The attitude in Sweden to the use of computers for learning was at that time extremely negative. A common perception was that computers should 
replace the teachers. Pedagogic theories based on behaviorism resulted in the use of programmed instruction where the students' paths were predefined; where the computer was mainly used for checking the progress of students and neither teachers nor students could influence the content or the methodology.

Projects demonstrating early uses of computers as cognitive tools strongly influenced PRINCESS. The most important ones were the work at Xerox with Allan Kay and Adele Goldberg (for instance Smalltalk, Dynabook, and its use ${ }^{6}$, at BBN with John Seely Brown, Allan Collins, and Wallace Feurzeig (for instance AI in CAI and use of a database system in geography ${ }^{4}$ ), and the Plato system at the Computer-based Education Research Laboratory (CERL) at University of Illinois headed by Donald Bitzer. ${ }^{10}$

When PRINCESS started, the hardware and software environments were very primitive; interactive systems were rare, terminals were primitive, personal computers were not available yet, communication was extremely expensive and most software lacked any signs of user-orientation.

\subsection{Goal, method and organization}

PRINCESS research should answer the questions if and how it could improve education by the use of computer aids. A model of a system for computer-based education (see Figure 2) was iteratively developed and evaluated. The research approach was interdisciplinary, emphasizing information processing and pedagogic. Activities included both basic and applied research. Furthermore, the research used a systems thinking with a holistic perspective, the conception that pedagogic requirements should influence the techniques and that people involved should participate in systems development. Development of methods and systems were interleaved with empirical studies.

Figure 2 presents our model of IT for learning. Normally only hard-, softand courseware were considered but we also took into account other aspects; methods for documentation, criteria for when we should use interactive systems, the environment in which to integrate IT for learning including both aspects that we had to influence and aspects we knew were impossible to change. Among these were changed roles of teachers and students, the interplay between IT and other media, and analysis of requirements on curricula and school development.

The model was developed in cooperation with users throughout the research. We implemented and studied situations as close as possible to regular use of IT for learning in schools. Four major stages of design, development, empirical tests, and evaluation were performed. The final 
period included almost all students, half of the teachers and many subject areas in Tibbleskolan outside Stockholm. Tibbleskolan is an upper secondary school with study programs in human and social sciences; the experimental period included around 1000 students and 80 teachers.

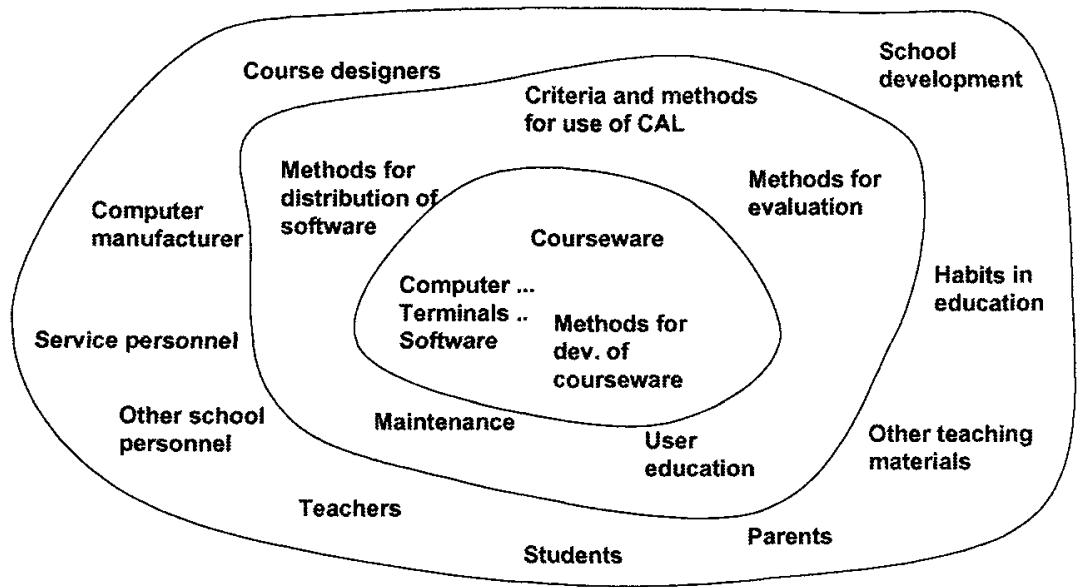

Figure 2. PRINCESS model in the frames and its surroundings

We analyzed existing methods of system development and found that they were not usable within PRINCESS and CLEA environments. Therefore, a special method (PUSUM) evolved, which received presentation in a doctoral thesis. ${ }^{21}$ We chose a DEC10-SIMULA environment for the development of courseware, thereby fulfilling the requirements of supporting realization of complex models. In this object-oriented environment, PRINCESS also created new tools for development of courseware, forming the program library PRINCIP including:

- DESIGN a tool to support development of the interactive parts

- Primitive tools for subject modeling in PRINCIP

- MAGIC a tool for development of computer assisted games for educational purposes.

PRINCESS used various terminal/workstations-teletypes, STANSAAB Graphics terminal, and Plato IV-Plasma-terminals. From this basis, the GLAS (Graphic Low cost Advanced System) concept evolved. GLAS allowed graphic presentation and we could use it as a terminal and as a high performance personal computer. The system was put together 1981 from components imported from the US. CLEA further developed GLAS to handle 16 million colors and to include the possibility to digitalize video signals. 
The main financiers of the project were the Swedish National Board for Technical Development (STU) and the Swedish National Board of Education SÖ. The total funding corresponding to 40 years of full-time work was extremely favorable. However, it should be taken into consideration that PRINCESS consisted of several sub-projects. The core research group included Anita Kollerbaur (project leader), Carl Gustaf Jansson, Hans Köhler, Louise Yngström, and Jerzy Hollenberg. The size of the group varied through the years.

The financiers appointed scientific advisors and a reference group to the project. Scientific advisors were Professor Börje Langefors of DSV and Professor Bengt-Olof Ljung from Pedagogics at the Stockholm Institute of Education. The reference group included financiers and representatives from different areas and organizations. The most important were Dir Arne Berglund of Mercator International Group, Professor Germund Dahlqvist of KTH, Nils-Erik Svensson of the Bank of Sweden Tercentenary Foundation, Lennart Levin of the National Swedish Board of Universities and Colleges, Thomas Ohlin of STU, Bengt Dahlbom and Esse Lövgren of NBE, and Stig Fägerborn and Peter Bagge of the Swedish Agency for Public Management.

\subsection{IT for learning - the PRINCESS approach}

PRINCESS applied the cognitive tool approach, implying that knowledge derives from the experience gained while performing meaningful activities, including analysis, reflection, and discussions. The students should be in the center and in control of the learning process. We regarded IT as one tool among other tools and materials. The tools enabled the students and the teachers to plan the learning situations and environments. Further the tools were designed to support students working in groups as we regard interactions among the learners of equal importance as individual interactions with the applications.

The use of computer aids was appropriate according to the PRINCESS approach when:

- The quality of teaching could be improved, for example to concretize and give better opportunities for project work and interdisciplinary studies

- Existing methods and other aids were insufficient, for instance by simulation of complex or dangerous realities

- It provided students and teachers with additional resources and offering more freedom

- Providing access to the special qualities of computers as means for handling and presenting information. 
Furthermore, an interactive program should make operations on nontrivial models available such as work with analytical models, information retrieval and simulation. It should also be easy to use, be flexible, easy to modify and develop. Figure 3 illustrates this approach.

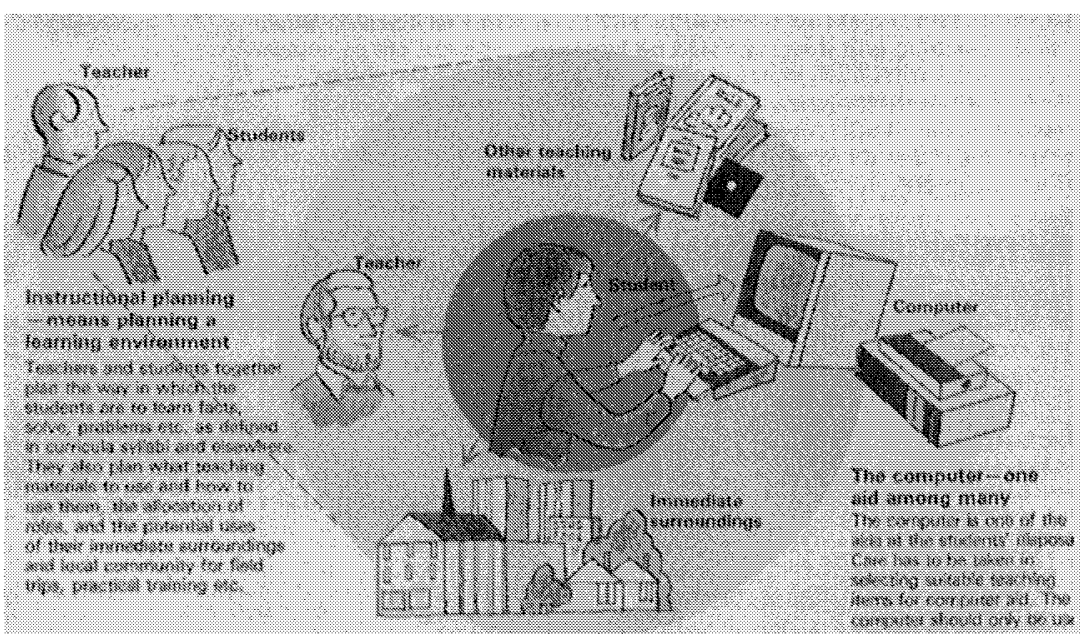

Figure 3: The popularized presentation of the

PRINCESS approach to IT for learning ${ }^{23}$

\section{SAMPLE OF APPLICATIONS}

One important goal for PRINCESS was to demonstrate the possibilities of IT for learning through applications within various subjects and learning situations.

\subsection{Traffic education}

One of the problems for primary education is to teach students safe traffic behavior. For that purpose a primitive simulator for riding a bike in a roundabout was developed in cooperation with STANSAAB, a Swedish Computer Company, and The National Road Safety Office.

The "bike" consisted of pedals (for speed) and handles (for maneuvering). Despite more like a moped, students perceived it as a real bike. Their task was to ride the bike trough the roundabout. Cars and other bikes, followed normal traffic rules and occasionally even randomly generated rule breaking rules occurred so students confronted different situations each time. Limited computer capacity did not allow repeated 
studies of how the use of the simulator changed the students' traffic behavior. Nevertheless, the few studies we made showed positive effects.

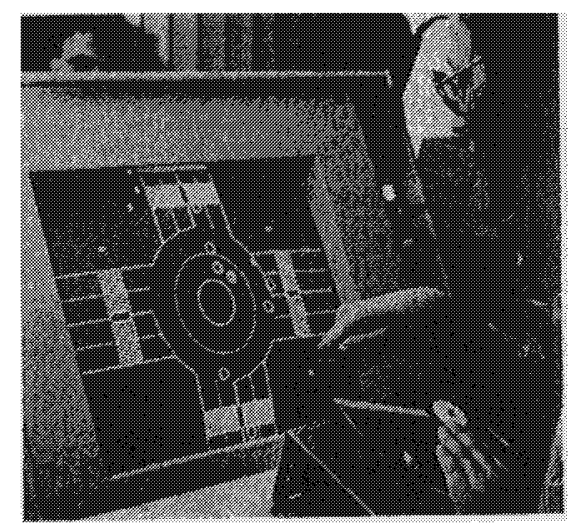

Figure 4: A simulator for riding a bike through a roundabout

\subsection{Mathematics}

Interactive graphics were used for heuristic mathematics teaching with a type of math lab, POLY. The computer aid made it possible for the students to study polynomial expressions and their graphic representations by constructing their own problems. POLY made it possible to study advanced problems in shorter time and was applicable with a number of methodological approaches and levels of study. It also proved to be useful in the teaching of arts and social sciences. In many cases, it transformed the students' attitudes and understanding of mathematics. A normal attitude towards math seemed to be that it should be boring and since students had fun working with the program, they themselves did not consider this learning mathematics.

\subsection{Application based on databases}

We made two major demonstrations of the use of databases: One in history and one in food sciences. We put extensive work into developing database-handling tools in SIMULA and user-friendly editors for the content of databases used by teachers themselves.

In both cases, we utilized professional, extensive sets of data from a demographic database, with data from the Swedish parishes of two communities 1821-1899. The researchers used the same data. In natural 
science, the database included data from a printed table published by Livsmedelsverket (National Food Administration) and from other expert bodies. Models of the subject area and functions for retrieving and presenting data were iteratively developed and tested. We used both programs for problem- and project-oriented learning.

In history, we could study individuals, families, and entire "clans". For each individual it was possible to retrieve a lifeline, setting out major events in his or her life. It was also possible to find persons in a particular family, their occupations, and other points of interest. Within a "clan", it was possible to retrieve the ancestors and descendants and get statistics about them. By combining these items, the students could find out a great deal about conditions in the $19^{\text {th }}$ century, doing their own research in history based on real data. This would have been impossible without computer aid.

In food science, a model of nutritional requirement together with the database, made it possible for the students to calculate nutritional requirements the nutritional balance - both allowing and disregarding individual activity - for individual meals, for an entire day, for a as well as the nutrient content of dishes and foodstuffs. The program, called KOST, also allowed searches for foodstuffs containing particular nutrients, development of nutritionally balanced recipes etc. With KOST, the students were able to use more advanced data than normally, they could also study their own problems. Functions for saving and retrieving data from students' projects made comparisons possible both for individual students, but also for collaborative learning. Diet surveys before and after the experiment showed that the students had grown more serious of the food they ate and that they had altered their eating habits. For the first time in school, students could do numerous experiments based on their own data, which was a strong motivating factor.

\section{STILL SUSTAINABLE RESULTS FROM PRINCESS}

It is striking that most of the main approaches and results from PRINCESS seem accurate also today. We were thirty years ahead or far too early. Some persons considered us as dreamers, our ideas would never be realizable on a broad scale.

The main results available in 1983 were:

- The use of the cognitive approach to IT for learning was possible, resulting in improved learning. Examples of courseware used the advantages of the technology, demonstrated numerous pedagogical use of each application including situated and collaborative learning. 
- Introducing computers as tools for learning was regarded as a process of change applying a holistic perspective; roles and processes were affected, mainly those of teachers and students.

- We perceived the difficulties to liberate our thinking on new lines, methods for stimulating creativity have to be applied, where teams covering different competencies cooperate; teachers, students, systems experts, interface experts and programmers.

- We stressed the communicative aspects of interactive systems; meaningful processes for learning demands support for communication of what we then called the subject model, support for navigation, orientation and for performing actions. Explicit presentation of the assumptions behind a subject model is required for appropriate learning. These are examples of early results in the area of Human-MachineInteraction, HMI.

- PRINCESS developed and used iterative methods for systems design and development with user participation, teamwork, repeated steps of design, development, and evaluation of prototypes. Combinations of evaluation methods from different disciplines were used depending on the stage of design, for instance participant observation and interviews at early stages. PRINCESS approach for design of interactive systems design is widely applied today.

- The object-programming environment with tools for different levels of a system to fulfill requirements on flexibility and maintenance, and the approach to represent systems to support both communication with users as well as implementation. However, programming competence was still required for developing courseware of the type PRINCESS aimed at. These were early demonstrations of modern software architecture, and tools.

- Finally, we demonstrated the importance of influencing the hardware and software environment from the user and use perspective.

\section{THE IMPACT OF PRINCESS}

\subsection{In schools}

The PRINCESS approach to the use of computers as pedagogical tools was fully agreed upon by the Swedish National Board for Education, and also influenced further activities in the area. Already in 1986, extensive financial support for courseware development was available and in addition, a group at the Ministry of Education and Science for coordination was established. Later, even more extensive support for the area was made 
available both from the ministry and from the Knowledge Foundation in Sweden.

The functional requirements applying to GLAS provided the base for a technical procurement project for a school computer, initiated by the National Board for Technical Development, resulting in the school computer COMPIS: (English for PAL). COMPIS went to market in 1985. However, the effort failed, partly due to the reason schools not accepting a dedicated system, partly due to the fast growing Mac- and PC-markets.

\subsection{Within academia}

Being a young group in a young department more oriented towards influencing the educational system rather than making academic careers, we made the mistake of publishing very few articles internationally before 1987. In total we produced three academic theses, ${ }^{9,21,29}$ four papers in English but a wealth of material, tools, methods, demos, software and articles in Swedish. The final documentation of the project appeared as a book in Swedish. ${ }^{23}$

However, the influence on research and education within our own department is substantial. Courses in computer-based education and humancomputer-interaction emerged in the mid 1970s. In 1993 the area grow into one of DSV's specializations for its master's program. The laboratory for Knowledge and Communication, K2lab, has its roots in PRINCESS and CLEA and is today the largest research laboratory at DSV. K2lab is led by one of the PRINCESS researchers, Carl Gustaf Jansson, now a professor at DSV.

\section{A NEED FOR A NEW APPROACH?}

Since 1986, the research and applications of IT for learning have grown, particularly during the late 1990 s, when the concept of e-learning became widely used often assuming the use of internet. Today, most of the obstacles perceived in PRINCESS - lack of computer power, limited multimedia facilities, problems with efficient communication, and high costs - are eliminated. New possibilities are available for distribution of education via Internet, technologies for computer-based cooperation, etc. Furthermore attitudes about the usefulness of computers in education are mainly positive nowadays.

Independent of all efforts put into to the area, the great breakthrough has not yet appeared in Sweden, at least not within the state financed educational system. An exception might be the Swedish Net University established in 
2002, planned to be a strong brand name for Swedish distance education provided by Swedish Universities.

There are certainly no simple explanations to why IT for learning is still in its infancy. The main forces behind the evolution of IT for learning are complex; interplay of many factors exists such as educational policies, attitudes, the economics involved and of course the technical developments. The large amount of perspectives and actors is partly illustrated in the PRINCESS model of Figure 2.

Could the main problem be that IT requires changed roles and processes that in turn requires time that is not available? Another reason could be costs; in schools it is difficult to find money for regular upgrading of equipment and teachers knowledge. A fact is that it is still too costly to develop high quality courseware. Is the reason that IT-tools are still not adapted to a widespread use? My personal view is that this requires tools available and usable analogous to paper and pencil. Another plausible explanation may be that the main approach has to be changed. Still today, established methods, content, and organization within education have only been transferred to a new medium.

Experiences from development, introduction, and use of IT in other areas have shown that the goal and content of activities within an organization, the working processes, and the relations are examples of aspects that should receive consideration in new perspectives. Very simply, this could also be expressed as IT applied to an existing organization neither saves costs nor increase quality, to make impact re-thinking is required.

The question then becomes, is our educational system properly organized for the society of today and tomorrow? Is there a need for a new approach? In addition, what would be a vision of a future educational system?

In 1994 such a vision was presented. It was based on the early experiences of IT for learning. The vision got its final form during a workshop with participants representing research within different academic areas, different educational areas and levels as well as industry and government. The goal was to create an environment for a lifelong, free and border-less learning. Figure 5 summarizes these ideas. The vision is documented in Swedish. ${ }^{32}$ In the following a few comments to the vision is presented. The main idea was that in the future we will have an individually controlled pedagogic, where basic knowledge, mentors, knowledge banks, and usable technology are available for all with the aim of supporting lifelong learning.

Centers of Knowledge are the meeting points for lifelong learning, a mixture of library, common meeting point, and schools. In the center all groups will meet, independent of age, interest, and country. It includes learners of all ages and study forms; compulsory school, adult education, enterprise courses and courses on university level. The Centers of 
Knowledge are nodes in a national and international net, thus establishing borderless learning environments making occasional study group possible. Completely new programs for education ought to be established and integrated: interdisciplinary studies are a reality. The view of classes and stages will to a large extent be changed; the classroom has become a virtual one. Groups will assemble according to interests, not on age. Individual study-plans completely organize education and lifelong CVs document the studies.

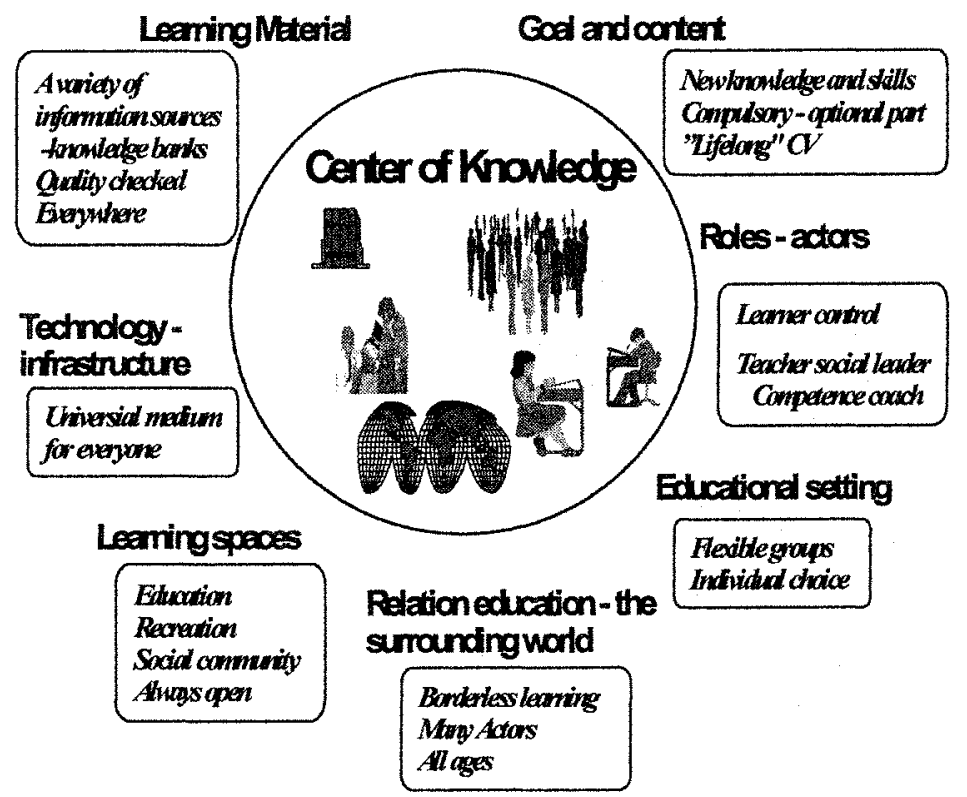

Figure 5: The 1994 vision for IT for learning

Goal and content for the curriculum has been revised, new knowledge and skills are defined to fulfill requirements of the future IT-based society. Roles are changed, the learner is in control; the teacher becomes a social leader and a competence coach. New actors appear, sometimes the learner becomes the coach for other learners, and seniors have become new important actors. Finally, the learning materials are to a large extent available everywhere via a variety of information sources. All materials used for learning have to be quality checked. IT is of course a prerequisite for realizing the vision and a universal medium adaptable for each use and individual is used. 
As this vision is almost 10 years by now it is time for a re-vision. Based on a new vision, research and development for future environments for learning, covering all aspects applying holistic approaches would guide us towards new thrilling experiences.

\section{REFERENCES AND BIBLIOGRAPHY}

The list is mainly chronologically ordered. For documents in Swedish, the headlines are translated.

[1] Teaching Machines and Programmed Study Material, NBE-document, 1962 (In Swedish).

[2] Computer mediated Education, Ministry of Education, 1966:8, 1966 (In Swedish).

[3] Lindecrantz N.: Computer-mediated Education, Studentlitteratur, 1968.

[4] Carbonell J.: AI in CAI, An Artificial Intelligence Approach to Computer-Assisted Instruction, IEEE Transactions on Man-Machine System, Dec. 1970.

[5] Stiernborg M.: The computer for Use in Education,-- an Overview of Computer-Assisted Instruction and Computer Managed Instruction, Rep. from Dept. of Education, Stockholm Univ., 1972 (In Swedish).

[6] Kay A., Goldberg A.: Personal Dynamic Media, Computer, vol 10, no 3, March 1972.

[7] The Computer in the School Community, (DISK), Pilot Study performed by Linköping Board for Education, Commission from NBE, NBE 1973 (In Swedish).

[8] IVA Special report USA, author A. Kollerbaur, IVA 1973:8 (In Swedish).

[9] Kollerbaur A.: Analysis of Systems for Computer-based Education, and Hypothesis for Future Research, Licentiate thesis, DSV, 1973 (In Swedish).

[10] Computers as Tools in Education, Conf. Proceedings 1973-10-02-03, STU information nr 19-1974 (In Swedish).

[11] Kollerbaur A., Köhler H., Yngström L.: Computers in Education, Data Processing Technology, TRITA- EDU-010, March 1975 (in Swedish).

[12] Collins A. et al: Reasoning from incomplete knowledge, Research and Understanding, Studies in Cogn. science, Academic Press 1975

[13] Yngström L.: A method for analysis and construction of interactive computer-based teaching programs, in Lecam, Lewis, (eds) Proceedings of IFIP Computers in Education, North-Holland/American Elsevier, 1975, pp 37-40.

[14] Kollerbaur A.: PRINCESS - a Project with User-Oriented, Interdisciplinary Approach to Computer-Based Education, Paper presented on a Sperry-Univac seminar i Rome 1976.

[15] PRINCESS; Document from a Conference on Computer-based Education 1977, TRITAIBADB-5003, DSV, 1977 (In Swedish).

[16] Brown J.S.: A paradigmatic example of Artificial Intelligent Instructional system, Proc of the First Int. Conf. on Applied General Systems Res. Resent Dev. and Trends, June 1977.

[17] Kollerbaur A, Jansson C-G J.: Computer-based Education - the State of the Art and Trends, Report from a Studies in the US and Canada 1978, PRINCESS activity report (In Swedish).

[18] Report from Swedish Delegation on Future Education \& Technology to Japan, SwedenJapan Foundation for Research and Development, April 1979.

[19] The Computer in the School (DIS), NBE's Action Program and Final Report, NBE Project 628, NBE 1980 (In Swedish). 
[20] Yngström L.: Interactive Computer Based Education, A General Description, in Lewis, Tagg (eds) Computer Assisted Learning, Scope, Progress and Limits, North-Holland, Amsterdam, N.Y., Oxford 1980, pp 173-183.

[21] Köhler H.: Methods for Systems Analysis and Development of Computer based Educational Systems, PhD thesis 1981, Dep. of Information Processing, Stockholm University/KTH, 1981, ISBN 97-7146-121-3 (In Swedish).

[22] Software and Hardware for the Swedish Schools (PRODIS-Project), Final report NBE Projcct 6205, NBE 1981(In Swedish).

[23] Kollerbaur A., Jansson C-G., Köhler H., Yngström L.: Computer Aids in Education PRINCESS Final Report, ISBN 91-970520-0-0, 1983 (in Swedish). A popular abstract in English, Computer Aids in education, Presenting the PRINCESS-project, DSV 1983.

[24] Kollerbaur, A.: Computers in Swedish Schools, report from Educational Research Workshop in Frascati, nov 1982, Council of Europe, Strasbourg 1983

[25] Datalär-84, Proceedings from a Conference about IT for learning for Teachers about Research, Development and Methods, ISBN 91-970520-1-9, Stockholm 1984 (In Swedish).

[26] Action Program för Education about Computers for Schools and for Adult Education, Ministry of Education, DsU 1986:10, Stockholm 1986 (In Swedish).

[27] CLEA progress reports 1980/81, 1981/82, 1982/83, 1983/84, 1984,/85, CLEA reports to STU, Dep. of Computer and Systems Sciences, DSV, Stockholm University/KTH.

[28] Jansson C-G.: Taxonomic Representations PhD Thesis, DSV 1985, ISBN 91-7170-991-6

[29] Kollerbaur A.: Summary of research in CLEA 1985/87, CLEA report to STU.

[30] Kollerbaur A.: (ed) Datalär-87 Proceedings, part I from a Conference about IT for learning for Teachers about Research, Development and Methods, ISBN 91-970520-2-7 (In Swedish).

[31] Kollerbaur A.: (ed) Datalär-87 Proceedings part II from a Conference about IT for learning for Teachers about Research, Development and Methods, ISBN 91-970520-3-5 (In Swedish).

[32] Kollerbaur A., Brunell M, et al: Learn with IT, Proposal for Research and Development for Change within Swedish Education, Electrumstiftelsen in Kista Science City, Dec 1994, (In Swedish). 